1 Nuffield Department of Population Health, University of Oxford, Oxford, UK

2 Clinical Effectiveness Unit, Royal College of Surgeons of England, London, UK

3 Cancer Epidemiology Unit, Nuffield Department of Population Health, University of Oxford

4 Department of Surgery, Oxford University Hospitals NHS Foundation Trust, Oxford, UK

5 Department of Health Services Research and Policy, London School of Hygiene and Tropical Medicine, UK

6 Public Health England, Birmingham UK

7 Department of Breast Surgery, St James's University Hospital, Leeds, UK

Correspondence to: D Dodwell david.dodwell@ndph.ox.ac.uk Cite this as: $B M J 2020 ; 371: m 4237$ http://dx.doi.org/10.1136/bmj.m4237 Published: 01 December 2020

\section{Treatment variation in early breast cancer in the UK}

\section{David Dodwell and colleagues examine why treatment variation continues to occur in breast cancer despite high quality evidence on best practice}
David Dodwell, ${ }^{1}$ Yasmin Jauhari, ${ }^{2}$ Toral Gathani, ${ }^{3,4}$ David Cromwell, ${ }^{5}$ Melissa Gannon, ${ }^{5}$ Karen Clements, ${ }^{6}$ Kieran Horgan ${ }^{7}$

One in seven women will develop breast cancer. Although the number of people diagnosed with this common disease is increasing, mortality continues to fall. In the UK, almost $80 \%$ of women diagnosed with breast cancer are alive 10 years after their initial diagnosis. ${ }^{1}$ The survival gains seen over recent decades have largely been achieved through earlier diagnosis and more effective treatments. Nonetheless, there is still room for improvement. Population based mortality for breast cancer among those aged $<75$ years in the UK ranges from 13 to 32 per $100000,{ }^{2}$ and UK survival rates from breast cancer are still reported to be below those in countries such as the United States and Australia. ${ }^{3}$

The treatment of breast cancer is multimodal, comprising local treatment (surgery and radiotherapy) and systemic treatments (endocrine therapy, chemotherapy, and biological therapy).

Breast conserving surgery is, in most cases preferred to mastectomy (removal of all the breast tissue) providing equivalent oncological outcomes, but with quality of life benefits. The choice of systemic therapies is driven by risk of recurrence, determined by stage, grade, and molecular pathological characteristics. For example, patients with ER (oestrogen receptor) positive cancer are treated with endocrine therapy and those with HER2 (human epidermal growth factor receptor 2) positive disease commonly receive trastuzumab and chemotherapy. Although randomised controlled trials have provided good evidence for optimal treatment, variation still occurs in the UK and may be one factor in reported lower survival rates.

\section{Treatment variation}

Surgery is the most important treatment for early breast cancer. The 2018 National Institute for Health and Care Excellence (NICE) guidelines maintain that patients should be treated "irrespective of age, with surgery and appropriate systemic therapy, rather comorbidity precludes surgery." 4

However, the National Audit of Breast Cancer in Older Patients has shown important differences among hospitals in the surgical care of older patients in England and Wales. For patients diagnosed between 2014 and 2016, rates of surgery varied from $85 \%$ to $100 \%$ (mean 96\%) in those aged 50-69 and from $46 \%$ to $97 \%$ (mean $76 \%$ ) in those aged $\geq 70 .{ }^{5}$ Among the same cohort, rates of breast conserving surgery were $46-85 \%$ in patients aged $50-69$ and $22-77 \%$ in those aged $\geq 70$ (table 1). than endocrine therapy alone, unless significant 
Table 1 | Reported variation in care for early breast cancer

\begin{tabular}{|c|c|c|c|}
\hline Example & Years of study & Reported variation in rates (\%) & Effect of variation \\
\hline \multicolumn{4}{|l|}{ Surgical care } \\
\hline Rate of surgery overall & $2014-16^{5}$ & $\begin{array}{l}\text { Patients aged 50-69: 85-100\% (mean 96\%) } \\
\text { Patients aged } \geq 70: 46-97 \% \text { (mean 76\%)*† }\end{array}$ & $\begin{array}{l}\text { Reduced survival, higher risk of locoregional } \\
\text { failure }\end{array}$ \\
\hline \multirow[t]{2}{*}{ Rate of breast conservation $v$ mastectomy } & $2014-16^{5}$ & $\begin{array}{l}\text { Patients aged } 50-69: 46-85 \% \\
\text { Patients aged } \geq 70: 22-77 \%{ }^{*}\end{array}$ & \multirow{2}{*}{$\begin{array}{l}\text { Loss of quality of life and psychological } \\
\text { wellbeing in patients denied an opportunity for } \\
\text { breast conservation surgery }\end{array}$} \\
\hline & $2014^{6}$ & $\begin{array}{l}47-64 \% \text { at regional level; } 8-81 \% \text { at surgeon } \\
\text { level }\end{array}$ & \\
\hline \multirow[t]{3}{*}{$\begin{array}{l}\text { Use of mastectomy with immediate breast } \\
\text { reconstruction }\end{array}$} & $2017-18^{7}$ & $\begin{array}{l}\text { 5-70\% (mean 28\%) for invasive disease. } \\
\text { 10-100\% (mean 49\%) for non-invasive } \\
\text { disease* }\end{array}$ & \multirow[t]{3}{*}{$\begin{array}{l}\text { Loss of quality of life; need for additional or } \\
\text { delayed surgical reconstruction treatment }\end{array}$} \\
\hline & $2000-14^{8}$ & 4-37\% (mean 10\%) for all patients ‡ & \\
\hline & $2008-09^{9}$ & $\begin{array}{l}\text { 9-43\% (mean: } 21 \% \text { overall, } 38 \% \text { for ductal } \\
\text { carcinoma in situ, } 17 \% \text { for invasive disease) } \ddagger\end{array}$ & \\
\hline $\begin{array}{l}\text { Use of initial surgery } v \text { primary endocrine } \\
\text { therapy in ER+ disease }\end{array}$ & $2014-17^{10}$ & $48-91 \%{ }^{*}+$ & $\begin{array}{l}\text { Increased risk of locoregional and distant } \\
\text { recurrence }\end{array}$ \\
\hline \multicolumn{4}{|l|}{ Adjuvant treatment } \\
\hline $\begin{array}{l}\text { Use of radiotherapy after surgery for invasive } \\
\text { disease }\end{array}$ & $2014-17^{11}$ & $\begin{array}{l}\text { Patients aged 50-69:69\% to } 99 \% \text { after breast } \\
\text { conservation surgery; } 32 \%-100 \% \text { after } \\
\text { mastectomy in patients aged 50-69 } \\
\text { Patients aged } \geq 70: 60 \%-97 \% \text { after breast } \\
\text { conservation; } 19-90 \% \text { after mastectomy* }\end{array}$ & $\begin{array}{l}\text { Higher locoregional recurrence risk, need for } \\
\text { further surgery and other treatments, survival } \\
\text { disadvantage in higher risk patients }\end{array}$ \\
\hline $\begin{array}{l}\text { Use of radiotherapy after breast conserving } \\
\text { surgery for DCIS }\end{array}$ & $2003-06^{12}$ & 0-100\% (median 58\%) at screening unit level & $\begin{array}{l}\text { Higher local recurrence risk, greater need for } \\
\text { subsequent surgery }\end{array}$ \\
\hline $\begin{array}{l}\text { Use of trastuzumab and chemotherapy for } \\
\text { HER2 positive disease }\end{array}$ & $2014-17^{1113}$ & $\begin{array}{l}\text { Patients aged 50-69:7-95\% } \\
\text { Patients aged } \geq 70: 11-72 \%{ }^{*}+\end{array}$ & $\begin{array}{l}\text { Higher risk of distant metastatic disease, } \\
\text { compromised survival }\end{array}$ \\
\hline
\end{tabular}

These contemporary examples mirror the variation in patterns of surgical practice seen around 20 years ago. The Breast Cancer Clinical Outcomes Measure Audit of symptomatically presenting breast cancer reported mastectomy rates that varied from $36 \%$ to $53 \%$, and $19 \%$ to $92 \%$ at regional and individual surgeon level, respectively. ${ }^{6}$

Older patients with ER positive early breast cancer may receive primary endocrine therapy (PET) rather than initial surgery for valid reasons-for example, serious comorbidity or short life expectancy. Figure 1 shows the percentage of women in England and Wales aged $\geq 70$ years receiving initial surgical treatment by NHS organisation and ER status. Substantial organisational variation occurred for women with ER positive cancer but not those with ER negative disease. ${ }^{10}$ This variation remained after adjustment for comorbidity and frailty, suggesting that different perceptions of appropriate care for women with ER positive disease may be responsible. ${ }^{14}$

Randomised controlled trials have found that primary endocrine therapy has inferior outcomes for local control and disease-free survival compared with initial surgery, ${ }^{15}$ and overuse of primary endocrine therapy may be associated with the poorer relative survival seen in the UK compared with other European countries. ${ }^{1617}$ 

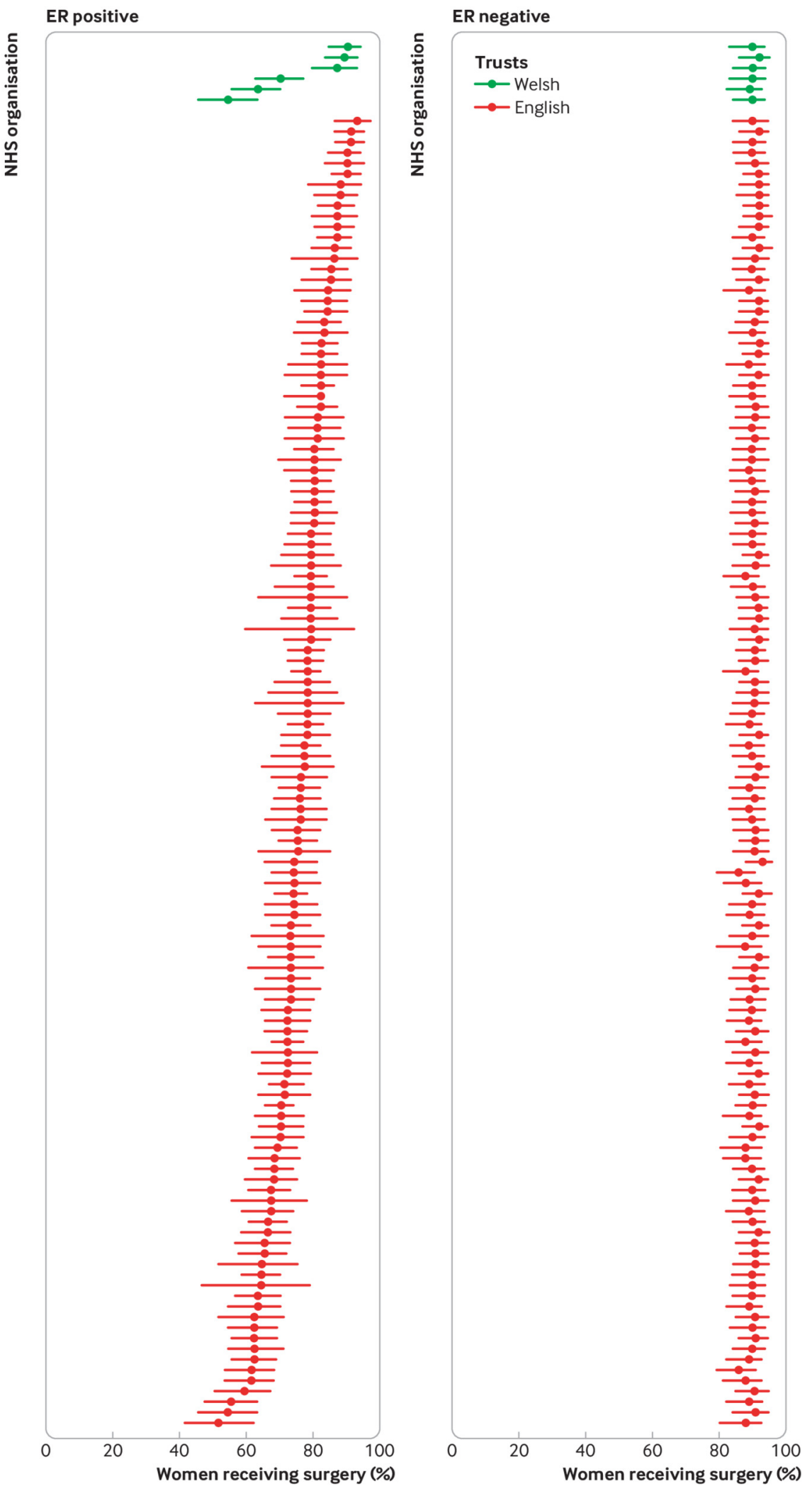

Fig 1 | Risk adjusted percentage ( $95 \%$ confidence interval) of women aged $\geq 70$ years receiving surgery as first treatment for early invasive breast cancer, by NHS organisation in Wales and England and oestrogen receptor (ER) status (redrawn with permission from HQIP) ${ }^{10}$

Substantial variation in clinical management extends to the use of radiotherapy, ${ }^{11} 1218$ adjuvant systemic therapy, ${ }^{1013}$ and immediate breast reconstruction..$^{7-9}$ (table 1). 


\section{Causes of treatment variation}

Many reports have highlighted inequalities in breast cancer care based on age, geography, ethnicity, and disability, ${ }^{2381017}$ but variation in the delivery of treatment persists even after trying to account for these factors. Furthermore, given the magnitude of variation across treatment methods, its persistence over time, and the large numbers of patients involved, the influence of factors such as patient preference or poor data quality is likely to be small.

The combination of rising breast cancer incidence and an increasing number of complex treatments has placed substantial demand on resources, and this may have contributed to variations in care. ${ }^{19} 20$ In England, the 2012 Health and Social Care Act led to the introduction of clinical commissioning groups. Although these groups were intended to improve the delivery and rationalisation of health services for diverse local populations, they also created an opportunity for differential introduction of new treatments because of disparities in local commissioning priorities and processes. This was seen with the introduction of adjuvant bisphosphonates after the identification of significant benefit in post-menopausal women. ${ }^{21}$ Bisphosphonates are inexpensive and yet there was prolonged geographical variation in their availability. It took three to four years from the publication of a definitive meta-analysis confirming benefit before prescribing in the UK became uniform. ${ }^{22} 23$

Although multidisciplinary teams should mitigate the effect of individual clinician preferences, clinicians may still be influenced by local practice, their involvement in clinical research, and the influence of their seniors. Several prominent trials of primary endocrine therapy occurred during the 1990 s and 200os, and these may have unduly influenced subsequent UK practice. ${ }^{24-26}$

\section{How to reduce variation in care}

Unexplained variation in care is not a new problem and has a reported history of over 80 years, encompassing a huge range of medical interventions. ${ }^{27}$ There are, however, many reasons to expect greater uniformity in the care of patients with early breast cancer in the UK. These include the NHS principle of equitable healthcare, the volume and accessibility of high quality published trial evidence, the emphasis on multidisciplinary approaches to care, the quality assurance processes for screen detected disease, the long history of national audits (see supplementary data on bmj.com), and, until recently, national cancer peer review.

NICE offers advice on the principles and practice of shared decision making, but its guidance that a treatment be "offered" (strong recommendation) or "considered" (less certain benefit) is arguably open to variable interpretation. Other countries differ in the strength of their advice. In Denmark treatments are "recommended."

Radiotherapy in uniform dose and fractionation is routinely provided after mastectomy for node positive invasive disease or breast conserving surgery. Deviations from national recommendations require explicit explanation in the patient's medical records and noting in the Danish Breast Cancer Group database. Jensen and colleagues reported that compliance with new or changed Danish breast cancer guidelines was over $90 \%$ within an average of one to two years. ${ }^{28}$

Other recent initiatives to reduce variation in care include a strengthened requirement for national clinical audits, supported and commissioned by the Healthcare Quality Improvement Partnership (HQIP), to identify outlying trusts (those with values $>2$ standard deviations (SDs from the mean for agreed performance indicators for care delivery and outcomes)). Trusts will be encouraged to review and understand outlying treatment rates that are $\geq 2$ SDs from the mean and investigate when $\geq 3$ SDs from the mean as part of their internal quality monitoring. This process will also support Care Quality Commission inspections using national clinical audit data. ${ }^{29}$

The Getting it Right First Time (GIRFT) initiative has established an ambitious programme of clinically led assessments of breast surgical services, including visits to trusts to understand and minimise undue variations in care. ${ }^{30}$ GIRFT's initial priorities are to reduce, where possible, length of stay after breast surgery in line with British Association of Day Surgery guidelines, to encourage open access follow-up to allow patients to determine when and how they interact with breast teams, and reduce unnecessary hospital attendances, operations, and tests. The GIRFT national report on breast surgery is awaiting publication.

The National Audit of Breast Cancer in Older Patients has published information on care pathways and treatment rates at trust level. ${ }^{11}$ The ready availability of data concerning care provision, that can be individualised to a trust, team, or clinician is a priority for national breast cancer audits and Public Health England. ${ }^{11} 31-33$ Transparency and accountability to promote debate, discussion, and audit are powerful tools in minimising the risk of substandard practice. The formal involvement of patients in national audits and in the governance activities of Public Health England is now routine and is key to ensuring that outputs reflect patient priorities as well as those of clinicians and policy makers. ${ }^{34}$

Variations in the care provided to patients with early breast cancer have been described over decades, and it has been easy to attribute these to poor data quality, case-mix differences, and patient choice. Lack of accord concerning optimum levels of intervention, defining unacceptable variation, and an inability to confirm causality from observational data are also serious obstacles in trying to confront this problem.

The management of breast cancer is closely studied in terms of national audit and related initiatives, but the effect of variation in care for other cancers is equally important to investigate and should be a focus for cancer charities and professional groups. HQIP already supports key national audits in gastrointestinal, lung, and prostate cancer. 35

\section{Key messages}

- Substantial variations occur in the care of patients with early breast cancer in the UK and may be leading to poorer outcomes

- Variation is of particular concern in management of older patients

- Patient factors cannot fully explain differences in treatment

- Data transparency and support for outliers may help reduce the gap between evidence and its uniform implementation

Competing interests: We have read and understood BMJ policy on declaration of interests and have no relevant interests to declare.

Provenance and peer review: Not commissioned; externally peer reviewed.

DD is funded by Cancer Research UK (grant C8225/A21133) and NABCOP. We thank Birgitte Offerson, Martine Bomb, and members of Independent Cancer Patients' Voice. NABCOP is commissioned by the Healthcare Quality Improvement Partnership and funded by NHS England and Improvement and the Welsh Government.

Cancer Research UK. Breast cancer statistics 2013-17. https://www.cancerresearchuk.org/healthprofessional/cancer-statistics/statistics-by-cancer-type/breast-cancer

All-Party Parliamentary Group on Breast Cancer. A mixed picture: an inquiry into geographical inequalities and breast cancer. 2018. https://breastcancernow.org/sites/default/files/appgbc_a_mixed_picture.pdf 
3 Organisation for Economic Co-operation and Development. Health Care Quality Indicators-Cancer Care. https://stats.oecd.org/

4 National Institute for Health and Care Excellence. Early and locally advanced breast cancer: diagnosis and management. NICE guideline NG101. 2018. https://www.nice.org.uk/guidance/ng101/chapter/Recommendations\#endocrine-therapy

5 National Audit of Breast Cancer in Older Patients. Annual report. 2018. https://www.nabcop.org.uk/reports/nabcop-2018-annual-report/

6 Breast Cancer Clinical Outcome Measures (BCCOM) Project. Analysis of the management of symptomatic breast cancers diagnosed in 2002. https://associationofbreastsurgery.org.uk/media/63920/final-7-bccom-report.pdf

$7 \quad$ NHS Breast Screening Programme, Association of Breast Surgery. Audit of screen detected breast cancer 2017-18. https://associationofbreastsurgery.org.uk/media/65088/nhsbsp-abs-audit-2017to-2018.pdf

8 Jeevan R, Mennie JC, Mohanna PN, O’Donoghue JM, Rainsbury RM, Cromwell DA. National trends and regional variation in immediate breast reconstruction rates. Br J Surg 2016;103:1147-56. doi: 10.1002/bjs.10161 pmid: 27324317

9 Association of Breast Surgery. A national audit of provision and outcomes of mastectomy and breast reconstruction surgery for women in England. Second annual report. 2009. https://associationofbreastsurgery.org.uk/media/1083/nmbra-annual-report-2009.pdf

10 National Audit of Breast Cancer in Older Patients. Annual report. 2019 [p28] https://www.nabcop.org.uk/content/uploads/2019/11/NABCOP-2019-Annual-Report-V1.1_highres.pdf

11 National Audit of Breast Cancer in Older Patients. NHS organisation data viewer. 2019. https://www.nabcop.org.uk/content/uploads/2019/05/NABCOP_AnnuaL_Report_2019_NHS_Organisation_Data_Viewer_LIVE_16052019.xIsX

12 Dodwell D, Clements K, Lawrence G, etalSloane Project Steering Group. Radiotherapy following breast-conserving surgery for screen-detected ductal carcinoma in situ: indications and utilisation in the UK. Interim findings from the Sloane Project. Br J Cancer 2007;97:725-9. doi: 10.1038/sj.bjc.6603945 pmid: 17848911

13 Gannon MR, Dodwell D, Jauhari Y, etal. Initiation of adjuvant chemotherapy and trastuzumab for human epidermal growth receptor 2-positive early invasive breast cancer in a population-based cohort study of older women in England. J Geriatr Oncol 2020;11:836-42. doi: 10.1016/j.jgo.2020.01.005 pmid: 32007402

14 Morgan JL, Collins K, Robinson TG, etal. Healthcare professionals' preferences for surgery or primary endocrine therapy to treat older women with operable breast cancer. Eur J Surg Oncol 2015;41:1234-42. doi: 10.1016/j.ejso.2015.05.022 pmid: 26108734

15 Hind D, Wyld L, Reed MW. Surgery, with or without tamoxifen, vs tamoxifen alone for older women with operable breast cancer: Cochrane review. Br J Cancer 2007;96:1025-9. doi: 10.1038/sj.bjc.6603600 pmid: 17285133

16 Derks MGM, Bastiaannet E, Kiderlen M, etalEURECCA Breast Cancer Group. Variation in treatment and survival of older patients with non-metastatic breast cancer in five European countries: a population-based cohort study from the EURECCA Breast Cancer Group. Br J Cancer 2018;119:121-9. doi: 10.1038/s41416-018-0090-1 pmid: 29875471

17 Breast Cancer Now. Age is just a number. The report of the parliamentary inquiry into older age and breast cancer. 2014. https://breastcancernow.org/sites/default/files/age-is-just-a-numberreport.pdf

18 Thompson AM, Clements K, Cheung S, etalSloane Project Steering Group (NHS Prospective Study of Screen-Detected Non-invasive Neoplasias). Management and 5-year outcomes in 9938 women with screen-detected ductal carcinoma in situ: the UK Sloane Project. Eur J Cancer 2018;101:210-9. doi: 10.1016/j.ejca.2018.06.027 pmid: 30092498

19 Royal College of Radiologists. New report reveals workforce crisis in UK breast cancer screening and diagnostic services. 2016. https://www.rcr.ac.uk/posts/new-report-reveals-workforce-crisis uk-breast-cancer-screening-and-diagnostic-services-0

20 Hignett K. Pensions crisis and staff shortages trigger record low cancer performance. Health Service Journal2019 Nov 1. https://www.hsi.co.uk/quality-and-performance/pensions-crisis-andstaff-shortages-trigger-record-low-cancer-performance/7026270.article

21 Early Breast Cancer Trialists' Collaborative Group (EBCTCG). Adjuvant bisphosphonate treatment in early breast cancer: meta-analyses of individual patient data from randomised trials. Lancet 2015;386:1353-61. doi: 10.1016/S0140-6736(15)60908-4 pmid: 26211824

22 National Institute for Health and Care Excellence. Early breast cancer (preventing recurrence and improving survival): adjuvant bisphosphonates. Evidence summary ES15. 2017. https://www.nice.org.uk/advice/es15/chapter/Key-points

23 Now BC. How we're increasing access to bisphosphonates. https://breastcancernow.org/aboutus/news-personal-stories/how-we\%E2\%80\%99re-increasing-access-bisphosphonates

24 Wylie S, Ravichandran D. A UK national survey of breast surgeons on primary endocrine therapy of early operable breast cancer. Ann R Coll Surg Engl 2013;95:353-6. doi: 10.1308/003588413X13629960045832 pmid: 23838499

25 Kornblith AB, Kemeny M, Peterson BL, etalCancer and Leukemia Group B. Survey of oncologists' perceptions of barriers to accrual of older patients with breast carcinoma to clinical trials. Cancer 2002;95:989-96. doi: 10.1002/cncr.10792 pmid: 12209681

26 Potter S, Mills N, Cawthorn SJ, Donovan J, Blazeby JM. Time to be BRAVE: is educating surgeons the key to unlocking the potential of randomised clinical trials in surgery? A qualitative study. Trials 2014;15:80. doi: 10.1186/1745-6215-15-80 pmid: 24628821

27 Mulley AG. Inconvenient truths about supplier induced demand and unwarranted variation in medical practice. BMJ 2009;339:b4073. doi: 10.1136/bmj.b4073 pmid: 19843566
28 Jensen MB, Laenkholm AV, Offersen BV, etal. The clinical database and implementation of treatment guidelines by the Danish Breast Cancer Cooperative Group in 2007-2016. Acta Oncol 2018;57:13-8. doi: 10.1080/0284186X.2017.1404638 pmid: 29202621

29 Healthcare Quality Improvement Partnership. Outlier management for national clinical audits. https://www.hqip.org.uk/outlier-management-for-national-clinical-audits/\#.X6fbeWj7RaQ

30 Getting it Right First Time. Breast surgery. https://gettingitrightfirsttime.co.uk/surgical-specialty/breast-surgery

31 Public Health England. Cancer dashboard. https://cancerdata.nhs.uk/dashboard

32 National Cancer Registration and Analysis Service. Cancer information tools. http://www.ncin.org.uk/cancer_information_tools

33 National Audit of Breast Cancer in Older Patients. Resources. https://www.nabcop.org.uk/resources 34 Independent Cancer Patients' Voice. Our aims. http://www.independentcancerpatientsvoice.org.uk/

35 Healthcare Quality Improvement Partnership. National clinical audit programme https://www.haip.org.uk/a-z-of-nca/\#.Xx6up/5KhaQ 